\title{
Determinação da Variação da Viscosidade Intrínseca do Poli (Tereftalato de Etileno) de Embalagens
}

\author{
Sandro D. Mancini \\ Instituto Politécnico, UNESP, Sorocaba \\ Itley G. Matos, Rômulo F. Almeida \\ Departamento de Engenharia Química, UFC
}

\begin{abstract}
Resumo: O mercado de embalagens de poli(tereftalato de etileno) -PET- para acondicionamento de refrigerantes, água mineral, sucos concentrados e óleos comestíveis apresenta polímeros de diferentes tipos, que foram desenvolvidos para personalizar o atendimento a clientes desejosos de propriedades melhores e mais específicas, principalmente em termos de massa molar. No caso do PET, assim como na indústria da reciclagem do polímero, o ensaio de viscosidade intrínseca é muito usado para determinar a massa molar. Este trabalho apresenta os resultados de viscosidade intrínseca de PET advindo de embalagens de várias marcas de refrigerantes, sucos e óleos de soja. Amostras de cada embalagem foram dissolvidas em solução de fenol-tetracloroetano (60:40 em peso) e o fluxo das mesmas em um viscosímetro CannonFenske a $30{ }^{\circ} \mathrm{C}$ para medir a viscosidade relativa, que foi convertido para viscosidade intrínseca. Os resultados mostraram uma variação no valor da propriedade conforme se variava o volume, tipo e a marca do produto envasado. Para as 21 amostras analisadas, os resultados variaram de 0,70 a $0,79 \mathrm{dL} / \mathrm{g}$. Portanto, uma melhor seleção das embalagens pode ajudar os recicladores na obtenção de produtos melhores, com menor variação na massa molar. Os valores de densidade obtidos apresentaram uma pequena variação, que torna-se maior quando transformados em cristalinidade.
\end{abstract}

Palavras-chave: PET, reciclagem, viscosidade intrínseca, massa molar e densidade.

\section{Determination of Intrinsic Viscosity Variation for Polyethyelene Terephthalate's bottles}

Abstract: The market of polyethylene terephthalate (PET) bottles presents polymers of different types, which have been developed in order to provide the client with products with improved properties, mainly in respect of molar mass. In the case of PET, as well as in the recycling industry of this polymer, the test of intrinsic viscosity is widely used to determine molar mass. This study presents the results of intrinsic viscosity and density for PET bottles of soft-drinks, juices and soybean oils. Samples of each bottle were dissolved in 60-40 phenol-tetrachloroethane solution and flowed into a CannonFenske viscometer at $30{ }^{\circ} \mathrm{C}$ to measure the relative viscosity, which was converted to intrinsic viscosity. The results have shown a change in the property, depending on the producer and volume. For the twenty-one samples analyzed, the viscosity varied from 0,70 to $0,79 \mathrm{dL} / \mathrm{g}$. Therefore, a best bottle's selection can help the recyclers to provide best products, with small variation of molar mass. The values of density obtained showed little variation, which increase when the results are converted to crystallinity.

Keywords: PET, recycling, intrinsic viscosity, molar mass and density.

\section{Introdução}

A indústria de embalagens de poli (tereftalato de etileno) -PET- tem a disposição um número grande de resinas virgens. Os fornecedores (fabricantes e importadores) procuram personalizar o atendimento, disponibilizando variações específicas para cada cliente e/ou produto. Isto demanda um controle de qualidade para garantir as propriedades das resinas e uma das principais propriedades de polímeros a ser verificada é a massa molar.

O índice de fluidez é um importante parâmetro tecnológico no controle de qualidade de polímeros e seu valor é inversamente proporcional à viscosidade do polímero fundido e sua massa molar. O PET, porém, é hidrolítico principalmente em temperaturas próximas às do processamento e do ensaio de índice de fluidez, podendo degradar durante o mesmo, fornecendo dificuldades experimentais e erros na medida.

Nas indústrias de PET virgem e reciclado, a medida mais difundida para fornecer a massa molar é a viscosidade intrínseca. Esta minimiza a hidrólise pois utiliza soluções em temperaturas relativamente baixas.

A viscosidade intrínseca pode ser convertida em massa molar viscosimétrica ou mesmo numérica média por meio

Autor para correspondência: Sandro D. Mancini, Instituto Politécnico, UNESP, Av. 3 de Março, 511, Alto da Boa Vista, CEP: 18087-180, Sorocaba, SP. E-mail:mancini@sorocaba.unesp.br 
de equações adequadas. Porém, este procedimento raramente é feito, sendo que a indústria prefere basear-se diretamente nos valores de viscosidade intrínseca.

No início do processo de reciclagem, as embalagens descartadas chegam à indústria recicladora em fardos separados por cor. Outra variação possível é a separação de frascos de óleo dos restantes, pois demandam uma lavagem diferenciada. Os fardos, com mais de mil frascos, são abertos e submetidos a um pente fino, que retira do processo impurezas como outros plásticos, metais e papéis. O restante é moído, lavado e normalmente reprocessado em extrusoras na forma de grânulos, cuja relação massa-volume é mais adequada para a fabricação de produtos finais em equipamentos convencionais, como injetoras e as próprias extrusoras (eventualmente, após a lavagem os flocos moídos podem ser processados na forma de produtos finais). Ou seja, o reciclador trata um número grande de embalagens diferentes, juntas. Dessa forma o produto final é uma mistura de várias resinas diferentes, com propriedades médias.

O objetivo deste trabalho é avaliar a variação da viscosidade intrínseca do PET de garrafas, conforme se altera o produto, marca e volume do frasco. Dessa maneira pode se propor intervenções no processo de seleção das embalagens para melhorar a qualidade do produto final, uniformizando a matéria-prima.

Serão expostos ainda alguns resultados sobre a variação da densidade dos flocos das embalagens moídas, de modo a auxiliar na proposição de alterações de processo. Um dos motivos para a escolha deste ensaio é o fato de densidades muito baixas poderem dificultar a descida do material no funil dos equipamentos de processamento, inviabilizando uma eventual mistura que pode ser feita entre material virgemfloco ou mesmo a produção de produtos finais a partir do floco. Este problema atinge, por exemplo, a reciclagem de filmes plásticos (densidade normalmente menor que $1 \mathrm{~g} / \mathrm{cm}^{3}$ ) e a de poliestireno (densidade inferior a $1,10 \mathrm{~g} / \mathrm{cm}^{3}$ ). Nestes casos, o mais usual na indústria da reciclagem é a adoção de uma etapa adicional, a aglutinação, em que os flocos passam por aquecimento e posteriormente por um choque térmico, mantendo a massa individual e contraindo o volume, aumentando assim a densidade. Ainda, a determinação da densidade por picnometria trata-se de um ensaio barato, o que o torna facilmente aplicável, caso julgado necessário.

\section{Experimental}

Foram selecionadas embalagens incolores descartadas de refrigerantes, sucos concentrados e óleos de soja de diferentes marcas, volumes e nomes de fantasia, comercializadas em Fortaleza-CE. De cada uma delas foi retirada uma amostra que foi lavada e seca e posteriormente, cortada em pequenos pedaços. Na lavagem (somente com água) e secagem foram utilizadas a temperatura ambiente e, após os quais, estavam prontas para os ensaios de viscosidade intrínseca e densidade.

Medidas convencionais de viscosidade intrínseca ([ๆ]) são normalmente realizadas a partir da medição da viscosidade relativa $\left(\eta_{\text {rel }}\right.$, quociente dos tempos de fluxo da solução polimérica e do solvente). Para este estudo, utilizou-se um dos métodos desenvolvidos para se obter a viscosidade intrínseca por meio de uma determinação única da relativa ${ }^{[1-3]}$.

Empregou-se a equação de Billmeyer (1) para estabelecer uma relação entre viscosidade relativa e a intrínseca, para concentrações otimizadas em $0,5 \%$ do polímero em volume de solução ${ }^{[2,4]}$. Como solvente do PET utiliza-se normalmente uma mistura de fenol e 1,1,2,2-tetracloroetano 60:40 em peso. Segundo a normalização, as medidas devem ser feitas a $30^{\circ} \mathrm{C}^{[4]}$.

$$
[\eta]=\frac{0,25\left\{\left(1-\eta_{r e l}\right)+3 \ln \eta_{r e l}\right\}}{c}
$$

onde $\mathrm{c}=$ concentração da solução contendo o polímero.

O sistema de dois solventes, a relação massa de polímero/ volume de solução, a temperatura da medida e a equação empregados nesse trabalho são comuns dentro de setores de pesquisa, desenvolvimento e controle de qualidade de PET no mundo todo.

As quantidades de polímero empregadas, adaptadas da normalização, foram $15 \mathrm{~mL}$ de solução e massa de polímero entre 0,0742 a $0,0757 \mathrm{~g}^{[4]}$. Utilizou-se para as medidas um viscosímetro de Cannon-Feske da Schott tipo 51313. Embora não seja o recomendado pela normalização, este viscosímetro mostra-se adequado ao ensaio por possuir tempo de fluxo para a solução -sem o polímero- igual a 115 segundos. A literatura determina que os tempos de fluxo da solução para ensaios de viscosidade de soluções diluídas devem ser superiores a 100 segundos para minimizar a necessidade de correções ${ }^{[5]}$.

Após a solubilização (com agitação, à $110^{\circ} \mathrm{C}$ ), resfriou-se a amostra e a solução foi transferida ao viscosímetro. O conjunto foi colocado num banho a $30^{\circ} \mathrm{C}$ por 15 minutos e iniciou-se a medida ${ }^{[4]}$. Esta consistiu na determinação do tempo de fluxo da solução polimérica (ou de eluição) numa dada região do viscosímetro, procedimento repetido quatro vezes. A média dos tempos de fluxo foi dividida pelo tempo de fluxo do solvente, obtendo-se $\eta_{\text {rel }}{ }^{[4]}$. Os dados foram obtidos eletronicamente pelo sistema Schott AVS 350.

Os resultados de viscosidade intrínseca foram transformados em massa molar numérica média $(\overline{M n})$ de acordo com a equação 2, de Berkowitz ${ }^{[5,6]}$. Segundo o autor, a validade da equação foi verificada para massas molares de 2000 a $200000 \mathrm{~g} / \mathrm{mol}$, a partir de medidas de viscosidade intrínseca (em condições semelhantes às utilizadas nesse estudo) e massa molar ponderal média $(\overline{M w})$ por cromatografia líquida de alta performance ${ }^{[6]}$. Esta última foi convertida por Karayannidis, Kokkalas e Biakiaris em $\overline{M n}$ a partir do índice de polidispersividade, $\overline{M w} / \overline{M n}=2$, normalmente encontrado para o $\operatorname{PET}^{[7]}$.

$$
\overline{M n}=3,29.10^{4}[\eta]^{1,54}
$$

Além da viscosidade intrínseca, foram também determinados os valores de densidade das amostras estudadas. Embora seja definida como a razão entre massa e volume, a densidade 
de partículas não necessariamente coincide com a do material, uma vez que, ocasionalmente, a partícula contém poros fechados que contam no volume da partícula. Para a medição das densidades das partículas, foi utilizado um picnômetro de $50 \mathrm{~mL}$, de massa conhecida $\left(\mathrm{m}_{0}\right)$, onde inicialmente introduziu-se a amostra. Posteriormente adicionou-se álcool etílico, até o picnômetro ficar totalmente preenchido. Quando o termômetro acoplado ao equipamento registrou $23{ }^{\circ} \mathrm{C}$ efetuou-se a pesagem de todo o conjunto, obtendo a massa da amostra com líquido $\left(\mathrm{m}_{\mathrm{SL}}\right)$. Tendo a massa do picnômetro cheio do líquido $\left(\mathrm{m}_{\mathrm{L}}\right)$ e a massa do picnômetro contendo as partículas $\left(\mathrm{m}_{\mathrm{S}}\right)$ e a densidade do líquido $\left(\rho_{\mathrm{L}}\right)$, calcula-se a densidade da partícula por meio da equação $3^{[8]}$. A densidade do líquido pode ser calculada com os resultados de $\mathrm{m}_{\mathrm{L}}$ dividido pelo volume do picnômetro. Determinou-se que a quantidade de $1 \mathrm{~g}$ (um grama) de material fornecia resultados repetitivos.

$$
\rho_{P}=\frac{\rho_{L}\left(m_{S}-m_{0}\right)}{\left(m_{L}-m_{0}\right)-\left(m_{S L}-m_{S}\right)}
$$

A relação proporcional existente entre cristalinidade e densidade fez com que alguns autores, que estudaram hidrólise de PET, preferissem a apresentação dos resultados de percentual cristalino, dado por:

$$
\% \text { Cristalinidade }=\% C=100 \times \frac{\rho-\rho_{a}}{\rho_{c}-\rho_{a}}
$$

onde foram utilizados dados encontrados na literatura para a densidade do material totalmente amorfo $(\rho \mathrm{a}=1,335 \mathrm{~g} / \mathrm{cm} 3)$ e do totalmente cristalino $\left(\rho \mathrm{c}=1,515 \mathrm{~g} / \mathrm{cm}^{3}\right)^{[9,10]}$.

\section{Resultados e Discussão}

As Tabelas 1 e 2 apresentam os resultados obtidos para vinte e uma amostras selecionadas, subdivididas em frascos incolores e verdes, respectivamente. Como o valor normalmente aceito para resinas que destinam-se a fabricação de frascos por meio de injeção-sopro é em torno de $0,73 \mathrm{dL} / \mathrm{g}$ e massa molar da ordem de $20.000 \mathrm{~g} / \mathrm{mol}$, observa-se que os resultados de todas as amostras podem enquadrar-se numa faixa ainda aceitável para uma eventual fabricação de frascos reciclados a partir das amostras ${ }^{[11]}$. Porém, a viscosidade da matéria-prima não é condição suficiente para a obtenção de um produto por meio de injeção-sopro. $\mathrm{Na}$ indústria da reciclagem de PET são feitos esforços para que a viscosidade não caia, o que dependerá principalmente de condições de secagem otimizadas (tempo, temperatura, atmosfera de secagem e de transporte para o equipamento de transformação). Dessa maneira, havendo matéria-prima com viscosidade intrínseca superior a $0,73 \mathrm{dL} / \mathrm{g}$, há a possibilidade da injeção-sopro deste material para a fabricação de novas embalagens por injeção-sopro.

Em termos de densidade/cristalinidade, após a fusão do material na injetora, é pouco provável a manutenção da estrutura totalmente amorfa do polímero fundido. Porém, é improvável o desenvolvimento da máxima cristalinidade possível, que pode atingir até $55 \%$. Isto porque, além do

Tabela 1. Resultados obtidos para a Viscosidade Intrínseca e Densidade de PET incolor utilizado em várias embalagens, bem como as Massas Molares e Cristalinidades calculadas a partir das equações 2 e 4, respectivamente.

\begin{tabular}{lcccc}
\hline \multicolumn{1}{c}{ Frasco } & $\begin{array}{c}{[\eta]} \\
\mathbf{d L} / \mathbf{g}\end{array}$ & $\begin{array}{c}\overline{\mathbf{M n}} \\
(\mathbf{g} / \mathbf{m o l})\end{array}$ & $\begin{array}{c}\text { Densidade } \\
\left(\mathbf{g} / \mathbf{c m}^{3} \mathbf{)}\right.\end{array}$ & $\begin{array}{c}\text { Cristalinidade } \\
(\mathbf{\%})\end{array}$ \\
\hline Coca-Cola 2,5L & 0,76 & 21560 & 1,397 & 34,4 \\
Coca-Cola 2,0L & 0,73 & 20260 & 1,368 & 18,3 \\
Coca-Cola 1,0L & 0,71 & 19415 & 1,373 & 21,1 \\
Coca-Cola 0,6L & 0,72 & 19837 & 1,394 & 32,8 \\
Pepsi-Cola 2,0L & 0,75 & 21125 & 1,365 & 16,7 \\
Pepsi-Cola 1,0L & 0,71 & 19415 & 1,360 & 13,9 \\
Frevo Cola 0,6L & 0,75 & 21125 & 1,368 & 18,3 \\
Água Mineral Indaiá 5L & 0,73 & 20260 & 1,368 & 18,3 \\
Água Mineral Indaiá 1,5L & 0,71 & 19145 & 1,373 & 21,1 \\
Água Mineral York 0,5L & 0,77 & 21998 & 1,368 & 18,3 \\
Óleo de Soja Liza 0,9L & 0,71 & 19415 & 1,384 & 27,2 \\
Óleo de Soja Soya 0,9L & 0,71 & 19415 & 1,359 & 13,3 \\
Suco Concentrado de Maracujá Maguary 0,5L & 0,70 & 18995 & 1,367 & 17,8 \\
Suco Concentrado de Caju Santal 0,5L & 0,70 & 18995 & 1,357 & 12,2 \\
\hline
\end{tabular}


Tabela 2. Resultados obtidos para a Viscosidade Intrínseca e Densidade de PET verde utilizado em várias embalagens, bem como as Massas Molares e Cristalinidades calculadas a partir das equações 2 e 4 , respectivamente.

\begin{tabular}{|c|c|c|c|c|}
\hline Frasco & $\begin{array}{c}{[\eta]} \\
\mathbf{d L} / \mathbf{g}\end{array}$ & $\begin{array}{c}\overline{M n} \\
(\mathrm{~g} / \mathrm{mol})\end{array}$ & $\begin{array}{c}\text { Densidade } \\
\left(\mathrm{g} / \mathrm{cm}^{3}\right)\end{array}$ & $\begin{array}{c}\text { Cristalinidade } \\
(\%)\end{array}$ \\
\hline Soda Antarctica 1L & 0,75 & 21125 & 1,355 & 11,1 \\
\hline Soda Antarctica 2L & 0,79 & 22884 & 1,389 & 30,0 \\
\hline Guaraná Antarctica 2L & 0,79 & 22884 & 1,376 & 22,8 \\
\hline Guaraná Antarctica $0,237 \mathrm{~L}$ & 0,78 & 22440 & 1,372 & 20,5 \\
\hline Sprite 2L & 0,73 & 20260 & 1,360 & 13,9 \\
\hline Limão Brahma 2L & 0,79 & 22884 & 1,395 & 33,3 \\
\hline Schin Limão 0,25L & 0,75 & 21125 & 1,361 & 14,4 \\
\hline
\end{tabular}

polímero poder ser uma versão copolimérica, não há tempo suficiente para que ocorra um nível de cristalização que reflita em ausência ou diminuição da transparência, devido ao resfriamento brusco e à espessura relativamente pequena da pré-forma e, futuramente, do frasco. Entretanto, formam-se regiões cristalinas em tamanho muito pequeno, as quais não conseguem provocar desvios sensíveis na trajetória da luz. Como limite máximo normalmente aceito para a cristalinidade deste tipo de embalagem, tem-se que a somatória das regiões cristalinas não deve exceder $25 \%{ }^{[12]}$.

Nota-se pela Tabela 1 que algumas amostras estão abaixo de $0,73 \mathrm{dL} / \mathrm{g}(20.000 \mathrm{~g} / \mathrm{mol})$. Assim, colocar todas as embalagens recebidas num mesmo processo fornecerá um polímero final com características médias, o que ajuda a explicar a grande utilização do PET reciclado como fibras sintéticas, aplicação que exige níveis de massa molar menores. A não ser que durante a reciclagem haja a estabilização da resina e/ou um rígido controle da atmosfera em contato com o polímero principalmente em altas temperaturas (em especial a partir de secagem e reprocessamento otimizados), é muito provável que o produto reciclado tem uma massa molar média inferior ao da embalagem original. Essa degradação durante a reciclagem é esperada na medida em que as cadeias macromoleculares serão submetidas a níveis de esforços mecânicos e de temperatura que, juntamente com agentes degradantes presentes nos equipamentos utilizados (como oxigênio e água, por exemplo) e mesmo remanescentes no polímero, vão ocasionar quebras de cadeia. Dependendo do nível dessas degradações e da massa molar inicial, o polímero reciclado pode ter uma massa molar abaixo do nível indicado para a fabricação de frascos, o que o direcionará para mercados cujas aplicações, no caso do PET advindo de garafas recuperadas, possuem um valor agregado menor.

As variações obtidas nos resultados de viscosidade intrínseca podem ser consideradas pequenas, de cerca de $10 \%(16 \%$ em termos de massa molar), embora ressalte-se que os valores mais próximos das embalagens verdes medidas $(8 \% \mathrm{em}$ termos de viscosidade e $13 \%$ em termos de massa molar) podem ter sido obtidos devido a amostragem menor. Devese considerar ainda que as medidas, de viscosidade, (assim como as de densidade), podem apresentar erros por não terem sido feitas repetições, embora tenham sido obtidos, para a mesma amostra, quatro tempos de eluição. Porém, tais variações situam algumas amostras abaixo do limite do PET grau garrafa, de forma que uma seleção mais criteriosa pode melhorar a qualidade do produto final. Neste sentido, uma separação por tamanho (maiores e menores que 2 litros) é possível e pode fornecer produtos mais homogêneos.

Numa medida realizada nos resíduos de PET de uma cidade brasileira, constatou-se que mais de $90 \%$ dos resíduos de PET eram frascos de refrigerante de $2 L^{[13,14]}$. Separadas, essas embalagens poderiam fornecer novos frascos, ressalvando-se a necessidade de uma reciclagem criteriosa em termos de manutenção da integridade macromolecular e as restrições existentes quanto ao uso de plásticos reciclados como embalagem de alimentos. As embalagens com menos de 2 litros poderiam ser direcionadas à indústria têxtil. Os principais produtos feitos de PET reciclado neste segmento, são fibras de segunda linha, utilizadas em aplicações pouco nobres como enchimentos.

Com relação aos resultados de percentual de cristalinidade, obtidos dos ensaios de densidade, os resultados da Tabela $1 \mathrm{e}$ 2 apresentaram uma variação grande, de cerca de três vezes do menor para o maior valor. Em que pese a ausência de repetições, que poderiam diminuir o valor das médias, esta dificuldade era esperada. Sabidamente, além do erro do próprio ensaio, existem diferenças na cristalinidade das embalagens devido à grande variedade de grades e de equipamentos para injeção existentes. Ou seja, cada amostra analisada corresponde ao produto da fusão de um polímero com determinado grau de cristalinidade e seu posterior resfriamento, que deve ser brusco para não permitir o máximo desenvolvimento e crescimento de regiões cristalinas de modo a permitir a transparência. Em termos de reciclagem essa variação não deve representar dificuldades, na medida em que, para serem reciclados, os flocos precisar ser fundidos, o que destrói toda a organização cristalina existente.

Analisando nas Tabelas 1 e 2 somente os resultados de densidade, foram obtidas, tanto para o incolor como para o verde, variações máximas da ordem de $3 \%$, o que indica que essa propriedade não deve ocasionar problemas de processo 
no caso de mistura dos mais variados tipos de embalagens (como por exemplo, problemas de fluxo nos funis dos equipamentos de transformação a serem utilizados para a fabricação de produtos reciclados). Valores de densidade inferiores a $1,10 \mathrm{~g} / \mathrm{cm}^{3}$ (filmes de polietileno, copos descartáveis de PS, etc) costumam demandar a etapa de aglutinação para tornar possível a extrusão-granulação. Os resultados obtidos ficaram bastante distantes desse valor limite.

O estudo apresentado coletou aleatoriamente um número de amostras menor ao universo de possibilidades comercializadas como embalagens de refrigerante, água mineral, óleo de soja e sucos concentrados na cidade de Fortaleza-CE. Apesar dessa aleatoriedade, uma generalização desses resultados para todas as embalagens comercializadas no Brasil é arriscada dada a quantidade de matéria-prima disponível fabricada no país ou importada, bem como as condições de processo (que podem variar, variando a viscosidade final) é grande. Assim, seria interessante que cada indústria fizesse um controle de qualidade de sua própria matéria-prima, baseado em ensaios de viscosidade, bem como uma correta análise dos resultados.

\section{Conclusões}

Dentre as amostras testadas, observou-se uma variação de valores de viscosidade intrínseca de cerca de $10 \%$ em termos de massa molar numérica média. Embora pequenas, essas variações podem ser suficientes para inviabilizar a fabricação de produtos de maior valor agregado ou simplesmente aumentar as opções do reciclador, por fornecer produtos com propriedades intermediárias. Para melhorá-las, os resultados indicam que a partir dos frascos com volume superior a 2 litros podem ser obtidos novos frascos, pois a viscosidade intrínseca deles é sempre superior a $0,73 \mathrm{dL} / \mathrm{g}$ (cerca de $20.000 \mathrm{~g} / \mathrm{mol}$ ), valor considerado como adequado para o processo de injeção-sopro de embalagens e que pode ser mantido (ou depreciado ao mínimo) por meio de um controle rigoroso de etapas de reciclagem, notadamente secagem e reprocessamento. Assim, uma separação destes frascos dos demais poderia garantir a obtenção de polímeros reciclados aptos a serem transformados em frascos, enquanto o restante poderia seguir para o segmento de fibras, que admite níveis de viscosidade intrínseca inferiores e para onde são direcionados a grande maioria do PET recuperado de resíduos domésticos. Esta separação é possível de ser feita, dada a grande quantidade relativa de frascos maiores de 2 litros em relação aos demais.

Já os resultados de densidade obtidos indicaram uma pequena variação que torna-se grande quando transformados em percentual de cristalinidade, o que não deve ocasionar problemas para o processo de reciclagem provavelmente trata-se de problemas experimentais, bem como de diferenças reais entre as amostras frutos de diferentes cristalizações obtidas em diferentes processos inejção-sopro.

\section{Agradecimentos}

Os autores agradecem à Profa. Assunção de Maria P.P. Timbó, à Profa. Luciana R.B. Gonçalves, bem como à Ana Cristina F. Colaço, Kelly A. Cavalcante, Louise L. Souza, Marcos B.S. Peixoto, Raquel C. Teixeira e ao Programa de Auxílio à Pesquisa para Recém-Doutores (Projeto Enxoval) da UFC.

\section{Referências Bibliográficas}

1. Conix, A. - Makr. Chem., 26, p. 226 (1958).

2. Shroff, R.N. - J. Appl. Polym. Sci., 9, 1547 (1965),

3. Solomon; O.F. \& Ciuta, I.Z. - J. Appl. Polym. Sci., VI, p. 683 (1962).

4. Am. Soc. Test. Mat. D4603-91, 1 (1991)

5. Billmeyer Jr., F. W. - "Ciencia de los Polímeros". Ed. Reverte, Barcelona, (1975)

6. Karayannidis, G. P. \& Bikiaris, D. N. - J. Appl. Polym. Sci., 50, 2135 (1993).

7. Berkowitz, S. - J. Appl. Polym. Sci., 29, p. 4353 (1984).

8. Gotoh, K.; Masuda, H. ; Higashitani, K. (Ed.). - "Powder Techonolgy Handbook”. Marcel Dekker Inc., $2^{\text {a }}$ Ed., Nova Iorque (1985).

9. Zhang, H. \& Ward, I. M. - Macromolecules, 28, p. 7622 (1995).

10. Thompson, A. B. \& Woods, D.W. - Nature, 176, p. 78 (1955).

11. Parashar, M. K. et al. - J. Appl. Polym. Sci., 67, p.1589 (1998).

12. Ehrig, R. J. "Plastics recycling: products and processes". Hanser Publishers, Nova Iorque (1992).

13. Mancini, S. D. - "Estudos de Hidrólise de PET PósConsumo no Estado Sólido Visando a Reciclagem Química", Tese de Doutorado, Universidade Federal de São Carlos, (2001).

14. Mancini, S. D. \& Zanin, M. - Pl. Ind., 25, p.118 (2000).

Enviado: $13 / 11 / 03$

Reenviado: 08/03/04

Aprovado: 15/03/04 